\title{
Development of ITM Oxygen Technology for Integration in IGCC \& Other Advanced Power Generation Systems (ITM Oxygen)
}

\author{
Technical Progress Report
}

for the period

July - September 2000

Robin E. Richards, Ph.D.

30 April 2001

DE-FC26-98FT40343

Air Products and Chemicals, Inc.

7201 Hamilton Blvd.

Allentown, PA 18195 


\section{Task 1.1: Optimize ITM Oxygen Materials}

The Pennsylvania State University (Penn State) installed the new test unit to measure high-temperature behavior of ITM Oxygen materials under oxygen permeation conditions. Penn State completed shakedown of the unit, supported by analysis performed by McDermott Technology, Inc., using thermal and mechanical models developed under Task 2.3.

Air Products, Penn State and Ceramatec, Inc. continued to measure physical and chemical property data for the ITM Oxygen material AP2K, in order to provide support for further development of detailed engineering models under Tasks 2.3 and 3.1 and ITM Oxygen process integrations under Task 2.6 .

\section{Task 1.2: Lifetime Testing of Optimized ITM Oxygen Materials}

Air Products demonstrated the ITM Oxygen flux target required for Task 4.3.1 Complete Evaluation of a Subscale Module of Subscale AP2K Membranes. The test was performed on a subscale membrane assembly at temperatures and oxygen partial pressures considered typical for full process conditions. Oxygen flux was measured in a Vacuum Permeate-Equipped Short Loop Test Rig unit at a feed-air pressure of 200 psig. Ceramatec prepared the subscale membrane under Task 3.2, using ceramic processing methods being developed for its baseline process. Subscale membrane performance tests indicate that the commercial ITM Oxygen flux target is achievable for an AP2K full-size membrane.

Air Products continued to perform oxygen flux tests of AP2K, laboratory-scale, supported, thin-film membranes, prepared by Ceramatec using baseline ceramic processing procedures. Laboratory-scale, supported, thin-film membranes are tested with an atmospheric pressure feed and a vacuum-permeate. Air Products also performed additional tests of ceramic-to-metal seal assemblies in the Short Loop Test Rig units with a pressurized air-feed.

Eltron Research, Inc. commenced work for its designed experiment study of ITM Oxygen material compositions, with the goal of identifying optimized compositions for the membrane and catalyst. Eltron Research prepared and characterized ceramic powder batches for each of the designed experiment material compositions it selected in the previous quarter. Since several compositions proved to be unattainable, Eltron Research successfully adjusted those target compositions in order to maintain the experimental design. Membrane fabrication and oxygen flux testing are in progress. Experiments to select the catalyst and optimize catalyst performance are also underway at Eltron Research.

\section{Task 2.1: Gas Turbine Integration}

Concepts NREC, Inc. provided support for Task 2.6.1 Process Engineering and Economic Evaluation for the IGCC Application by collaborating with Air Products on turbine engine performance calculations. Several scenarios were examined for the ITM 
Oxygen and cryogenic ASU-integrated IGCC base cases being developed by Texaco, Inc. and Air Products under Task 2.6.1. Concepts NREC calculated turbine engine performance for the state-ofthe-art engine selected under Task 2.1.3 in the previous quarter.

\section{Task 2.3: Thermal and Mechanical Analysis of Membranes and Seals}

McDermott Technology, Inc. performed additional analyses of the ITM Oxygen membrane structure to support the selection and definition of suitable tests for validating mechanical modeling results. The modeling validation tests will be performed under Task 3.1.

\section{Task 2.4: Conceptual Process Vessel Design Engineering}

McDermott Technology continued to develop conceptual designs for commercial process vessels to house full-size ITM Oxygen membrane modules.

\section{Task 2.6: Process Engineering and Economic Evaluation}

Under Task 2.6.1, Texaco and Air Products held the second technical meeting for the joint process engineering and economic evaluation of IGCC power plants employing Texaco's gasification technology. Texaco and Air Products constructed base cases around an identical state-of-the-art turbine engine and Texaco gasifier for both an ITM Oxygen-integrated and a cryogenic ASU-integrated facility and agreed on the scope of study and cost estimate categories. Concepts NREC provided support through turbine engine performance calculations for the two IGCC base cases and Texaco's initial syngas compositions. Air Products and Concepts NREC evaluated several scenarios (see Task 2.1 above) and transmitted them to Texaco for its review and recommendation.

\section{Task 3.1: Membrane Design and Engineering}

McDermott Technology selected and completed the definition of two candidate tests for validating its approach and property assumptions used for mechanical modeling of ITM Oxygen membrane structures. For the first candidate test, an initial round of diagnostic experiments was performed successfully with a range of membrane samples prepared by Ceramatec. For the second candidate test, referred to as a "pressure-collapse-test," McDermott Technology will use strain-gauged membrane samples. The design and assembly of the "pressure-collapse-test" equipment is in progress at McDermott.

\section{Task 3.2: Membrane Fabrication}

In July, Ceramatec transitioned its baseline ceramic processing development from the intermediate-size ITM Oxygen membrane to the full-size membrane. Operating conditions for the baseline tools were set through designed experiments with full-size membranes, or based on the experience gained from processing intermediate-size membranes. Significant progress was achieved, with testable full-size 
membranes successfully produced for commissioning the Technology Development Unit (TDU) under Task 4.2. Full-size membranes will be performance tested in the TDU under Task 4.3. Ceramatec continued to develop control charts for the repeated baseline process. As a result, processing improvements are being pursued to improve the yield of in-specification membranes, to improve processing equipment reliability, and to increase the throughput of membranes. Scaleup of baseline membrane-processing throughput has been substantial to date. When expressed as the total membrane area processed per quarter, Ceramatec has achieved a 16-fold increase for this quarter compared to the period October-December 1999.

\section{Task 3.3: Membrane Fabrication Pilot Line}

Ceramatec completed the hazards review for the ceramic processing tools in the Stage I structure. Ceramatec also installed a Stage II ceramic processing tool in a dedicated, temporary structure, held the hazards review and initiated tool shakedown to support processing of full-size membranes. The Stage II ceramic processing development facility design was finalized, and contract placement discussions were initiated. The Stage I and II facilities will be used under Task 3.2 to further develop procedures for the full-size membranes.

\section{Task 3.5: Advanced Module Development}

Ceramatec has further developed its novel bonding method for ITM Oxygen module construction. This alternative fabrication approach has enabled significant progress and provided promising results, leading to the selection of a preferred system for more detailed study and development. The preferred system was used to assemble near leak-tight samples. Ceramatec is investigating the effects of varying the processing conditions and procedures to develop this "Advanced Module" method.

\section{Task 4.2: Design and Construction of the TDU}

Air Products completed the Design Hazards Review for the Technology Development Unit (TDU) and finalized the P\&ID. Significant progress was achieved with the installation of TDU components, and the new compressor has been commissioned successfully against the performance requirements. The TDU will test full-size membrane components at commercially relevant conditions. 